\title{
Common factors method to predict the carcass composition tissue in kid goats $^{1}$
}

\author{
Helen Fernanda Barros Gomes ${ }^{2}$, Heraldo Cesar Gonçalves ${ }^{3}$, Angelo Polizel Neto ${ }^{2}$, Gil Ignacio \\ Lara Cañizares ${ }^{3}$, Roberto de Oliveira Roça ${ }^{3}$, Raquel Ornelas Marques ${ }^{3}$, Giuliana Micai de \\ Oliveira $^{3}$, Edicarlos Oliveira Queiroz ${ }^{3}$
}

\author{
${ }^{1}$ Financed by Fundação de Apoio à Pesquisa do Estado de São Paulo. \\ ${ }^{2}$ Universidade Federal de Mato Grosso/UFMT, Sinop - MT, Brazil. \\ ${ }^{3}$ Universidade Estadual Paulista Júlio de Mesquita Filho/UNESP, Botucatu - SP, Brazil.
}

\begin{abstract}
The objective of this work was to analyze the interrelations among weights and carcass measures of the longissimus lumborum muscle thickness and area, and of sternum tissue thickness, measured directly on carcass and by ultrasound scan. Measures were taken on live animals and after slaughter to develop models of multiple linear regression, to estimate the composition of shoulder blade, from selected variables in 89 kids of both genders and five breed groups, raised in feedlot system. The variables considered relevant and not redundant on the information they carry, for the common factor analysis, were used in the carcass composition estimate development models. The presuppositions of linear regression models relative to residues were evaluated, the estimated residues were subjected to analysis of variance and the means were compared by the Student $t$ test. Based in these results, the group of 32 initial variables could be reduced to four variables: hot carcass weight, rump perimeter, leg length and tissue height at the fourth sternum bone. The analysis of common factors was shown as an effective technique to study the interrelations among the independent variables. The measures of carcass dimension, alone, did not add any information to hot carcass weight. The carcass muscle weight can be estimated with high precision from simple models, without the need for information related to gender and breed, and they could be built based on carcass weight, which makes it easy to be applied. The fat and bones estimate models were not as accurate.
\end{abstract}

Key Words: co-linearity, correlation, evaluation, goat, regression

\section{Introduction}

In Brazil, there are no standards for the marketing of goat meat, neither are there established cuts. Carcasses are usually sold as whole or half carcasses, with no differences regarding the payment for those with the greatest proportion of prime cuts (leg, shoulder and loin). This also happens in other countries, including those where meat goat production is more traditional, such as Portugal, where the market of animals or carcasses only uses live body weight or carcass weight as the main variable to set the marketing price (Cadavez et al., 2002).

The tissue composition of the carcass would be the most correct manner of classifying and paying of marketed carcasses, since the body composition of animals of all species varies as a result of growth, nutrition and their genetics, and the percentage of muscle in the bodies of the animals ranges from 35 to $50 \mathrm{~kg} / 100 \mathrm{~kg}$ body weight. So, it is easy to admit that their economic value depends on the composition of their carcass (Topel \& Kauffmam, 1988). In this regard, many studies were conducted to determine the composition of the carcasses, with the use of indirect measures taken on the live animal and correlations, or by complete dissection or some carcass cuts after slaughter, but generally, models developed to estimate carcass composition use multiple and linear regressions and are based on the coefficient of determination and the residual standard deviation to assess the quality of the adjustment, but they do not take into account the inter-relationships among the independent variables in order to meet the information collected therein.

The development of multiple linear regression models using correlated independent variables may present limitations in their inference and accuracy, and they are likely to present serious effects on estimates of regression coefficients and on the general applicability of the estimated model.

The analysis of common factors has been identified as an alternative to the development of models for multiple linear regression, and biased data is a method that allows re-expressing data in terms of a number of common factors, in order to reduce the number of multivariate data 
(Johnson \& Wichern, 1988). With this methodology, it is possible to obtain a reduced number of variables without losing information in the original set of variables.

This work wascarriedoutto analyze theinterrelationships between weights and measurements of carcasses, evaluated directly on the carcass and by ultrasound on the live animal and to develop multiple linear regression models to estimate the composition of the shoulder of goats raised in feedlot by using the method of common factors.

\section{Material and Methods}

Eighty-nine animals were used in this experiment. Of those, 51 were males and 38 were females. The animals were from five breed groups: 11 were Alpine (A); $71 \frac{1}{2}$ Boer $+1 / 2$ Alpine $(1 / 2$ BA $) ; 111 / 2$ Alpine $+1 / 2$ Anglo Nubian ( $1 / 2$ ANA); $113 / 4$ Boer $+1 / 4$ Alpine ( $3 / 4$ BA); and 11 were $1 / 2$ Anglo Nubian+ $1 / 4$ Boer $+1 / 4$ Alpine (Tree Cross, TC). Among the females, 4 were A; 11 were $1 / 2 \mathrm{BA}$; 9 were $1 / 2$ ANA; 8 were $3 / 4$ BA; and 6 were TC (Table 1).

At birth, kids were separated from their mothers, weighed and identified with necklaces. They were fed colostrum and were housed according to their sex and breed group in ten collective pens $(2.0 \times 3.0 \mathrm{~m})$. They were artificially fed the maximum supply of 1.5 liters/day of cow or goat milk, divided into two daily supplies until 10 days of age and after that only a daily supply until weaning at 60 days of age. Then they started receiving the total experimental diet, which consisted of pellets containing 30:70 of oat hay:concentrate, with the following composition: $490 \mathrm{~g} / \mathrm{kg}$ of corn, $380 \mathrm{~g} / \mathrm{kg}$ of soybean meal, $100 \mathrm{~g} / \mathrm{kg}$ cottonssed meal, $20 \mathrm{~g} / \mathrm{kg}$ limestone and $10 \mathrm{~g} / \mathrm{kg}$ mineral salt.

The day before slaughter, ultrasound images were collected from the thoracic-lumbar region on the longissimus muscle on the left side, between the 12th and 13th ribs and in the sterna region between the $3 \mathrm{rd}$ and 4 th sternebrae. Measures of breast edge width, height at the withers and body condition score (BCS; ranging from 0 (very thin) to 5 (extremely fat), subjectively assessed by palpation in

Table 1 - Distribution of the experimental animals according to breed group and sex

\begin{tabular}{lcccccc}
\hline \multirow{2}{*}{ ex } & \multicolumn{6}{c}{ Breed } \\
\cline { 2 - 7 } & $\mathrm{A}$ & $1 / 2 \mathrm{BA}$ & $1 / 2 \mathrm{ANA}$ & $3 / 4 \mathrm{BA}$ & $\mathrm{TC}$ & Total \\
\hline Male & 11 & 7 & 11 & 11 & 11 & 51 \\
Female & 4 & 11 & 9 & 8 & 6 & 38 \\
Total & 15 & 18 & 20 & 19 & 17 & 89 \\
\hline
\end{tabular}

A - Alpine; $1 / 2$ BA - Boer $\times$ Alpine; $1 / 2$ ANA - Anglo Nubian $\times$ Alpine; $3 / 4$ BA - 1/2 BA $\times$ Boer; $\mathrm{TC}-1 / 2 \mathrm{BA} \times$ Anglo Nubian. the lumbar region) were also obtained (Silva Sobrinho \& Gonzaga Neto, 2006).

The animals were slaughtered at approximately 110 days of age (ranging from 63 to 119 days of age) in a commercial slaughter house, inspected by SISP, after a 24-hour water deprivation, and they presented shrunk weight ranging from 6.90 to $24.80 \mathrm{~kg}$. After slaughter, the carcasses were evaluated subjectively on the conformation and fat cover. They were weighed to obtain the hot carcass weight $(\mathrm{HCW})$ and refrigerated at $4{ }^{\circ} \mathrm{C}$ for 24 hours and weighed again to obtain the cold carcass weight. Commercial carcass dressing was calculated. After that, the carcass biometric measurements were taken, in which the following were measured using an adapted methodology of Sañudo \& Sierra (1986): carcass inner length, carcass outer length, chest depth, perimeter of the leg, length of the leg, rump perimeter, rump width and chest width.

Soon after, the carcass was separated into seven commercial cuts, by adapted methodology of ColomerRocher et al. (1987): shoulder, neck, chest-abdomen, uncovered rib, rib, loin and leg, which were weighed to calculate their yield, separating the longissimus muscle, which had its area drawn on transparent paper to determine the loin eye area and its depth through software SPLAN Sistema de Planimetria (Silva et al., 1993).

The depth of the tissues was also measured at the 3rd and 4th sternebrae and the carcass compactness index was calculated by the ratio between the weight of the cold carcass and carcass internal length. The leg compactness index was calculated by the ratio between rump width and leg length (Table 2).

Because of the high correlation among the tissues composing the carcass and shoulder (Arguello et al., 2001), the latter was selected as a way of representing the carcass. Thus, the shoulder was left for dissection and determination of the amount of muscle, bone, total fat and their proportions.

Firstly, to analyze the interrelationships between HCW and other measures taken on the live animal and after slaughter, the 32 features were subjected to analysis of correlation and common factors (Johnson \& Wichern, 1988).

The factor analysis is a method that allows for reexpressing data in terms of a number of common factors, in order to reduce the number of multivariate data (Johnson $\&$ Wichern, 1988). This procedure is based on the fact that any set of $p$ continuous variables $x 1, \ldots . ., x p$ observed in each of $n$ experimental units can be transformed into a new set of variables.

These new variables are called common factors f1, ......, $\mathrm{fp}$, and each $\mathrm{fj}$ variable is a linear combination of the 
Table 2 - Description the measurements taken on the live animal, biometric measures, carcass indices and meat cuts

Measures obtained on the live animal

\begin{tabular}{ll}
\hline SW & Live weight after 24 hours of water deprivation $(\mathrm{kg})-$ shrunk weight \\
BEW & Breast edge width, measured with a caliper $(\mathrm{cm})$ \\
WH & Height at the withers $(\mathrm{cm})$ \\
BCS & Body composition score, ranging from 0 to 5 \\
$3-4 S-U S$ & Depth of the tissues from the 3rd to the 4 th sternebrae, measured by ultrasound \\
LD-US & Depth of the loin between the 12 th and 13 th ribs, measured by ultrasound
\end{tabular}

Biometric measures of the carcass and index

$\begin{array}{ll}\text { HCW } & \text { Hot carcass weight }(\mathrm{kg}) \text { right after slaughter } \\ \text { CCW } & \text { Cold carcass weight after 24 hours of cooling }(\mathrm{kg}) \\ \mathrm{CCD} & \text { Carcass commercial dressing }(\mathrm{HCW} / \mathrm{SW}) \\ \mathrm{CIL} & \text { Inner length of the carcass }(\mathrm{cm}) \text {, from the anterior edge to the pubis to the edge of the 1st rib } \\ \mathrm{COL} & \text { External length of the carcass }(\mathrm{cm}) \text { between the cervical-thoracic articulation and 1st intercoccygeal joint } \\ \text { CONF } & \text { Carcass conformation, with a subjective evaluation ranging from } 1 \text { to } 5 \\ \text { FC } & \text { Fat cover, with subjective evaluation ranging from } 1 \text { to } 5 \\ \text { CD } & \text { Chest depth }(\mathrm{cm}), \text { measured behind the shoulder } \\ \text { LP } & \text { Perimeter of the leg }(\mathrm{cm}), \text { above femur-tibia articulation } \\ \text { LL } & \text { Length of the leg }(\mathrm{cm}), \text { from the largest trochanter of the femur to the tarsometatarsal articulation } \\ \text { RP } & \text { Perimeter of the rump }(\mathrm{cm}), \text { based on the trochanters of the femur } \\ \text { RW } & \text { Width of the rump }(\mathrm{cm}), \text { maximum width between trochanters of femur } \\ \text { CW } & \text { Width of the chest }(\mathrm{cm}), \text { maximum width of the breast } \\ \text { CCI } & \text { Carcass compactness index }(\mathrm{HCW} / \mathrm{CIL}) \\ \text { LCI } & \text { Leg compactness index }(\mathrm{RW} / \mathrm{LL}) \\ 3-4 S T & \text { Depth of the tissues between the 3rd and 4th sternebrae, measured with a caliper }(\mathrm{cm}) \\ \text { LD } & \text { Depth of the loin between the 12th and 13th ribs }(\mathrm{cm}) \\ \text { LEA } & \text { Loin eye area }\left(\mathrm{cm}^{2}\right)\end{array}$

Meat cuts

SHOULDER Shoulder $(\mathrm{kg})$, scapula, radio, ulna and carpus

NECK Neck $(\mathrm{kg})$, seven cervical vertebrae

CHEST-ABDOMEN Chest-abdomen $(\mathrm{kg})$, based on the lower half of the ribs and sternum up to the intersection of the abdominal muscle

1-5RIB Uncovered rib ( $\mathrm{kg}$ ), five first chest vertebrae

6-13RIB Rib (kg), region from the 6th and 13th ribs

LOIN Loin $(\mathrm{kg})$, region of the lumbar vertebrae

LEG Leg $(\mathrm{kg})$, sacra vertebrae and two first coccygeal vertebrae, ilium, ischium, pubis, femur, tibia and tarsus

original variables $\mathrm{x} 1, \ldots . ., \mathrm{xp}$, i.e., $\mathrm{fj}=\mathrm{v} 1 \mathrm{jx} 1+\mathrm{v} 2 \mathrm{jx} 2+\ldots+$ vpjxj, where $\mathrm{j}=1,2, \ldots . ., \mathrm{p}$ so that the linear combinations are chosen so the variables $\mathrm{fl}, \ldots . . ., \mathrm{fp}$ are orthogonal or independent.

The analysis of factor allows the partition of variance of each of the original variables into common variance (shared with some or all variables) and single variance (specific for a given variable). By using this method, it is possible to obtain a reduced number of variables, common factors, without losing the information contained in the original set of variables. Thus the use of this analysis is indicated for:

1. Understanding the size of the data, i.e., to know the measure of each of the variables;

2. Reducing the number of the original variables under study, removing the redundant ones;

3. Replacing the original variables by a small group of new variables assigned by factors, which parsimoniously describe the original data, with the exception of what they represent.

Therefore, this procedure aimed at selecting this set of initial independent variables, a small group of variables, with the objective ofminimizing theloss ofinformation concerning the set of the 32 variables. The Factorial Analysis of SAEG (Sistema para Análises Estatísticas e Genéticas, version 9.0) was used in the experiment.

The variables considered relevant in non-redundant information they carry were selected by the first analysis of common factors and subjected to a second analysis of common factors to obtain a set of new variables, common factors, which were also used in developing estimate models of carcass composition. Three types of models to estimate the carcass composition were developed.

Model 1 was obtained by simple linear regression, using the $\mathrm{HCW}$ as an independent variable. This model was considered as the basis for comparison of the other models, since the weight of the carcass is a piece of information always available at a very low cost.

In model 2, the $n$ features selected from the first processing were used as independent variables, for adjustment of the multiple regression equations. A significance level of 0.05 was adopted for admission of the independent variables. 
In model 3, the new variables (common factors) generated from the analysis of common factors of variables selected from the first processing were used as independent varibales, adopting the same level of significance of the model type 1 .

The three models assessed can be represented as follows:

Model 1:y $=\beta_{0}+\beta_{1} H C W+e$;

Model 2: $y=\beta_{0}+\sum_{1}^{4} \sum_{1}^{4} \beta_{i j} C S_{i j}+e$;

Model 3: $y=\beta_{0}+\sum_{1}^{4} \sum_{1}^{4} \beta_{i j} F C_{i j}+e$;

Where:

$\mathrm{y}=$ dependent variable of the carcass composition, amount and content of muscle, fat and bones; $\beta_{0}=$ constant; $\beta_{1}=$ regression coefficient of hot carcass weight $(\mathrm{HCW}) ; \beta_{\mathrm{ij}}=$ regression coefficient for the independent variables and common factors in the carcass multivariate models; $\mathrm{CS}_{\mathrm{ij}}=$ selected features; $\mathrm{FC}_{\mathrm{ij}}=$ common factors; and $\mathrm{e}=$ random error.

The quality of model adjustment was assessed by using coefficient of determination $\left(\mathrm{R}^{2}\right)$ and residual standard deviation (RSD).

$$
\mathrm{RSD}=d p y \sqrt{\left(1-R^{2}\right)(n-1) /(n-2)} ;
$$

Where:

$d p y=$ standard deviation of the dependent variable (Montgomery, 1997); and $\mathrm{n}=$ number of observations.

In the linear regression analysis, the authors of this study assumed that the errors satisfy certain assumptions, assuming that they present means equal to zero, follow normal distribution, have constant variance (homoscedasticity) and are independent. The verification of these hypotheses is very important, since any statistical inference in linear regression models (hypothesis testing) is based on these assumptions, only justifying the use of models when there are no violations. For detection of these violations, the analysis of residues is the most commonly used. Thus, some specific statistical tests were used, such as the test of Lilliefors (Lilliefors, 1967), which is used to test the assumption of normality. The assumptions of mean zero, homoscedasticity and independence of the residues can be checked graphically representing the residues according to the estimated values of the dependent variable, or as a function of the values of one of the independent variables. However, violations of the assumptions are not always easy to detect when using a residual plot, and errors may occur, so the test of Durbin Watson can be used to evaluate the independence between successive residues (Neter et al., 1990).
The quality of adjustment of the models to the data can be evaluated using statistics that measure the correlation between the observed and estimated values, and the coefficient of determination $\left(\mathrm{R}^{2}\right)$ and the residual standard deviation (RSD) are frequently used to evaluate the capabilities of estimating models (Montgomery, 1997), where in the latter is particularly important in comparing statistical models developed in different samples (Kempster, 1984).

Thus, the assumptions of linear regression models for residues had the assumptions of normal distribution of the residues evaluated by the test of Lilliefors (Lilliefors, 1967); the homogeneity of the residues (homo or heteroscedasticity) was evaluated by analysis of graphs of studentized residues versus estimated values, and the Durbin Watson, to evaluate the independence of the residues (Hoffmann \& Vieira, 1987).

The mean of the residues $\left(\sum_{i=1}^{n}\left(y_{i}-\breve{y}\right) / n\right)$ and the mean of absolute value of the residues $\left(\sum_{i=1}^{n}\left|y_{i}-\breve{y}_{i}\right| / n\right)$ were also calculated to evaluate the bias and deviation of models for sex and breed group. The estimated residuals were subjected to analysis of variance in order to find out if the models are biased or not, and whenever the effect was significant $(\mathrm{P}<0.05)$, means were compared using the Student $t$ test.

A linear independence of the independent variables of the models was evaluated by the Variance Inflation Factor (VIF), which examines the value of $\mathrm{R}^{2}$ resulting from the regression between each of the independent variables and all others. The variance inflation factor for the variable $\mathrm{X}_{\mathrm{i}}$ is $\mathrm{VIF}=1 /\left(1-R^{2}\right), i=1,2, \ldots, \mathrm{p}$.

If $X_{i}$ has a strong linear relationship with the other independent variables, then the $\mathrm{R}^{2}$ will be close to 1 and IVF will be high, and when IVF has values above 10, this means that there are some issues concerning collinearity of the data (Neter et al., 1990).

The software used for evaluation of the data was SAEG (Sistema para Análises Estatísticas e Genéticas, version 9.0), developed at Universidade Federal de Viçosa, MG, Brazil.

\section{Results and Discussion}

The weight at fasting in this study showed very variable values, with an amplitude of $17.90 \mathrm{~kg}$ (6.90 to 24.80), reflecting on the hot carcass weights with a variation of $7.85 \mathrm{~kg}$ between the lightest ones and the heaviest ones (3.60 to 11.45). Due to this amplitude, some coefficients of 
variation $(\mathrm{CV})$ were quite high. It should be noted that the thickness of tissues in the sternal region and the percentage of fat in the shoulder presented the highest $\mathrm{CV}$, which were around 34 and $30 \%$, respectively. Similar behavior was observed for the measures of total thickness of tissues in the sternal region. Fat thickness, loin eye area (LEA) and leg width, as well as some carcass cuts (chest-abdomen, rib and loin) had CV greater than $20 \%$. The ultrasound data, index, carcass weight, conformation score, leg perimeter, weight of muscles and bones had CV lower than $20 \%$, and despite the large amplitude observed in the weight of animals, dimensions of the data obtained on the live animal showed low coefficients of variation, less than $10 \%$.

When the variables of shoulder composition were expressed in percentage, a reduction in their coefficients of variation was found, especially evident in the coefficient of variation in the ratio of muscle which was reduced to $3.73 \%$, showing a reduction of $79 \%$, and in a similar manner, the coefficient of variation of the proportion of bones decreased by around 40.5\% (15.37 vs 9.15\%).

The low coefficients of variation of the dimension measures of the carcass found in this study corroborate the data of Shahin et al. (1993), who observed coefficient of variation between 5 and $14 \%$ in length measurements (which reflect the growth of the bones) and widths (which reflect the development of the adipose and muscular tissues, respectively) (Butterfield \& Thompson, 1983) (Table 3).

The CV of muscle weight and depth of rib was very similar to weight at fasting and to the hot carcass weight, which may be a reflection of those measures, which, according to Cadavez (2004), can be explained by the isometric growth shown by the muscular tissue in relation to the weight of the carcass. It is expected that changes in carcass weight directly reflect the variation of weight of the muscle and in the variables associated with it.

When percentage was used to express the proportion of muscle, bone and fat, which corresponds to a correction of the variable, there was a large reduction in $\mathrm{CV}$ of the muscle and bone. This, according to Butterfield (1988) and Cadavez (2004) with respect to the muscle, is associated with the low variability in the proportion of muscle in the carcass, which remains more or less constant over the growth.

Cadavez (2004) also reported that the amount of fat in the carcass has a high $\mathrm{CV}$, at around $60 \%$ for fat thickness but decreasing to $33 \%$ when reducing the variation in carcass weight. According to the author, this high $\mathrm{CV}$ has been observed by several authors, and is justified by the late maturation of adipose tissue in relation to the weight of the carcass.
According to Butterfield (1988) and Butterfield \& Thompson (1983), the subcutaneous fat (which reflects the status of the animal fattening) is that of highest $\mathrm{CV}$, affected by the ratio of the weight of the animal at slaughter with their mature weight, which explains the values obtained in this study.

When the linear correlation coefficients are evaluated (Table 4), it can be seen that all variables had at least one correlation value above 0.70 with any other variable, which means the existence of collinearity among variables. It was also found that the characteristics of weight at fasting, hot and cold carcass weight are those which exhibit higher and positive correlations with most of the other characteristics, showing presence of high collinearity among them.

Table 3 - Mean, maximum and minimum values and coefficient of variation $(\mathrm{CV})$ of the independent variables assessed and tissues of the shoulder

\begin{tabular}{|c|c|c|c|c|}
\hline Variable & Mean & Minimum & Maximum & CV $(\%)$ \\
\hline Shrunk weight (kg) & 18.81 & 6.90 & 24.80 & 16.96 \\
\hline Breast edge width $(\mathrm{cm})$ & 4.69 & 3.00 & 6.11 & 12.87 \\
\hline Whither height $(\mathrm{cm})$ & 53.68 & 40.50 & 61.00 & 7.41 \\
\hline BCS (from 0 to 5 ) & 3.01 & 2.00 & 4.00 & 13.55 \\
\hline 3-4S-US (cm) & 19.97 & 11.90 & 26.90 & 13.72 \\
\hline LD-US (cm) & 18.73 & 13.60 & 25.70 & 12.25 \\
\hline Hot carcass weight (kg) & 8.37 & 3.60 & 11.45 & 17.56 \\
\hline Cold carcass weight $(\mathrm{kg})$ & 7.85 & 3.25 & 10.90 & 17.88 \\
\hline Commercial dressing & 0.41 & 0.36 & 0.47 & 5.57 \\
\hline Inner length (cm) & 43.91 & 33.00 & 50.00 & 6.84 \\
\hline Outer length (cm) & 48.07 & 37.00 & 56.00 & 7.59 \\
\hline Conformation ( 0 to 5 ) & 2.40 & 1.25 & 3.75 & 18.42 \\
\hline Fat cover ( 0 to 5$)$ & 1.76 & 1.00 & 3.50 & 26.66 \\
\hline Thorax perimeter $(\mathrm{cm})$ & 56.56 & 45.00 & 62.00 & 5.87 \\
\hline Leg perimeter $(\mathrm{cm})$ & 27.91 & 22.00 & 34.00 & 8.79 \\
\hline Length of the leg $(\mathrm{cm})$ & 28.46 & 24.00 & 33.00 & 7.67 \\
\hline Rump perimeter $(\mathrm{cm})$ & 37.82 & 28.00 & 47.00 & 9.75 \\
\hline Rump width (cm) & 13.66 & 10.70 & 18.00 & 9.97 \\
\hline Chest width (cm) & 19.89 & 11.50 & 27.40 & 22.83 \\
\hline Carcass compactness index & 0.17 & 0.09 & 0.24 & 14.85 \\
\hline Leg compactness index & 0.48 & 0.36 & 0.67 & 11.75 \\
\hline $3-4 \mathrm{ST}(\mathrm{cm})$ & 1.52 & 0.50 & 2.50 & 34.04 \\
\hline Loin depth $(\mathrm{cm})$ & 2.58 & 1.50 & 4.00 & 18.29 \\
\hline Loin eye area $\left(\mathrm{cm}^{2}\right)$ & 8.33 & 3.91 & 14.85 & 28.24 \\
\hline Shoulder (kg) & 0.81 & 0.38 & 1.09 & 16.02 \\
\hline Neck (kg) & 0.30 & 0.15 & 0.49 & 20.64 \\
\hline Chest-abdomen (kg) & 0.60 & 0.17 & 1.02 & 29.70 \\
\hline Uncovered rib (kg) & 0.27 & 0.11 & 0.57 & 32.52 \\
\hline Rib (kg) & 0.36 & 0.13 & 0.57 & 21.16 \\
\hline Loin $(\mathrm{kg})$ & 0.41 & 0.13 & 0.62 & 21.37 \\
\hline $\operatorname{Leg}(\mathrm{kg})$ & 1.19 & 0.51 & 1.80 & 18.92 \\
\hline Fat (kg) & 0.08 & 0.02 & 0.16 & 34.23 \\
\hline Muscle (kg) & 0.51 & 0.24 & 0.71 & 17.48 \\
\hline Bone $(\mathrm{kg})$ & 0.21 & 0.11 & 0.29 & 15.37 \\
\hline$\%$ fat $(\%)$ & 9.34 & 4.24 & 18.46 & 30.35 \\
\hline$\%$ muscle $(\%)$ & 63.78 & 56.00 & 68.55 & 3.73 \\
\hline$\%$ bone $(\%)$ & 26.45 & 20.64 & 34.16 & 9.15 \\
\hline
\end{tabular}

BCS - body condition score; 3-4S-US - tissue thickness from the 3rd to the 4th sternebra obtained by ultrasound.

LD-US - loin depth obtained by ultrasound; 3-4ST - tissue thickness between the $3 \mathrm{rd}$ and the 4 th sternebrae measured with a caliper. 
Table 4 - Coefficient of the linear correlation among the 32 assessed independent variables

\begin{tabular}{|c|c|c|c|c|c|c|c|c|c|c|c|c|c|c|c|}
\hline Variable & SW & BEW & WH & $\mathrm{BSC}$ & 3-4S-US & LD-US & $\mathrm{HCW}$ & $\mathrm{CCW}$ & $\mathrm{CCD}$ & CIL & $\mathrm{COL}$ & CONF & FC & $\mathrm{CD}$ & LP \\
\hline \multicolumn{16}{|l|}{$\overline{\text { SW }}$} \\
\hline BEW & 0.6613 & & & & & & & & & & & & & & \\
\hline WH & 0.6631 & 0.2209 & & & & & & & & & & & & & \\
\hline 3-4S-US & 0.6789 & 0.4350 & 0.3585 & 0.4092 & & & & & & & & & & & \\
\hline LD-US & 0.7442 & 0.5007 & 0.3733 & 0.5581 & 0.6499 & & & & & & & & & & \\
\hline $\mathrm{HCW}$ & 0.9551 & 0.6483 & 0.6248 & 0.4176 & 0.7065 & 0.7467 & & & & & & & & & \\
\hline CIL & 0.7196 & 0.2418 & 0.8437 & -0.1431 & 0.4104 & 0.3872 & 0.6727 & 0.6688 & -0.1054 & & & & & & \\
\hline $\mathrm{COL}$ & 0.7037 & 0.2442 & 0.8146 & -0.1530 & 0.3762 & 0.3759 & 0.6681 & 0.6678 & -0.0476 & 0.8679 & & & & & \\
\hline CONF & 0.4927 & 0.4039 & 0.1359 & 0.4641 & 0.4409 & 0.4736 & 0.5548 & 0.5753 & 0.3181 & 0.1584 & 0.1819 & & & & \\
\hline $\mathrm{FC}$ & 0.1443 & 0.1326 & -0.1045 & 0.3132 & 0.1388 & 0.1833 & 0.2027 & 0.2183 & 0.2387 & -0.1284 & -0.1170 & 0.4778 & & & \\
\hline $\mathrm{CD}$ & 0.7035 & 0.3066 & 0.6838 & 0.0815 & 0.4857 & 0.5474 & 0.7163 & 0.7329 & 0.1380 & 0.6766 & 0.6475 & 0.3977 & 0.1919 & & \\
\hline LP & 0.0917 & -0.2246 & 0.1848 & 0.1081 & 0.1204 & 0.080 & 0.1828 & 0.2053 & 0.3261 & 0.1562 & 0.1679 & 0.2838 & 0.3624 & 0.3472 & \\
\hline CCI & 0.8676 & 0.6832 & 0.4029 & 0.6006 & 0.6955 & 0.7603 & 0.9371 & 0.9448 & 0.3148 & 0.3970 & 0.4497 & 0.6492 & 0.3329 & 0.6205 & 0.2085 \\
\hline LCI & 0.1385 & 0.1875 & -0.2043 & 0.5803 & 0.2059 & 0.2906 & 0.2107 & 0.2232 & 0.2682 & -0.2247 & -0.2175 & 0.5357 & 0.3668 & 0.1065 & 0.2308 \\
\hline $3-4 \mathrm{ST}$ & -0.1382 & -0.2857 & 0.0608 & -0.0101 & -0.0260 & -0.0993 & -0.0868 & -0.0649 & 0.1929 & -0.0574 & -0.0903 & -0.0174 & 0.1355 & 0.1190 & 0.5549 \\
\hline LD & 0.4370 & 0.2163 & 0.1340 & 0.5407 & 0.5208 & 0.4966 & 0.5116 & 0.5173 & 0.2703 & 0.1850 & 0.1568 & 0.4700 & 0.4046 & 0.3634 & 0.3851 \\
\hline LEA & 0.6305 & 0.5903 & 0.1916 & 0.6102 & 0.5095 & 0.5847 & 0.6262 & 0.6260 & 0.0552 & 0.2161 & 0.2037 & 0.5320 & 0.2866 & 0.3567 & -0.0941 \\
\hline $\mathrm{SHO}$ & 0.8971 & 0.5090 & 0.6938 & 0.3016 & 0.6777 & 0.6756 & 0.9379 & 0.9385 & 0.2015 & 0.7138 & 0.6814 & 0.5345 & 0.2223 & 0.7840 & 0.2832 \\
\hline NECK & 0.5437 & 0.1712 & 0.5354 & 0.1349 & 0.4264 & 0.3879 & 0.6406 & 0.6515 & 0.3671 & 0.528 & 0.4913 & 0.3196 & 0.2453 & 0.6445 & 0.5876 \\
\hline CHEST-ABD & 0.8047 & 0.6391 & 0.4403 & 0.3313 & 0.5692 & 0.6231 & 0.8132 & 0.7963 & 0.0521 & 0.4533 & 0.5183 & 0.429 & 0.1395 & 0.4635 & -0.0596 \\
\hline $1-5 \mathrm{RIB}$ & 0.7842 & 0.6409 & 0.4927 & 0.2231 & 0.4841 & 0.5863 & 0.7566 & 0.7503 & -0.0257 & 0.5378 & 0.5785 & 0.3574 & -0.0565 & 0.5083 & -0.1580 \\
\hline 6-13RIB & 0.8054 & 0.5220 & 0.6319 & 0.3127 & 0.5570 & 0.6054 & 0.8286 & 0.8391 & 0.1734 & 0.6826 & 0.6512 & 0.4607 & 0.0736 & 0.6728 & 0.1905 \\
\hline LOIN & 0.8514 & 0.5806 & 0.4679 & 0.4884 & 0.5955 & 0.7028 & 0.8614 & 0.8644 & 0.1138 & 0.5896 & 0.5848 & 0.5207 & 0.2475 & 0.5604 & 0.1282 \\
\hline LEG & 0.9418 & 0.6822 & 0.6044 & 0.4086 & 0.6648 & 0.7452 & 0.9502 & 0.9440 & 0.0931 & 0.6407 & 0.6479 & 0.4644 & 0.1376 & 0.6417 & 0.0444 \\
\hline
\end{tabular}

Continuation of Table 4 .

\begin{tabular}{|c|c|c|c|c|c|c|c|c|c|c|c|c|c|c|c|c|}
\hline Variable & LL & $\mathrm{RP}$ & RW & $\mathrm{CW}$ & $\mathrm{CCI}$ & LCI & $3-4 \mathrm{ST}$ & LD & LEA & $\mathrm{SHO}$ & NECK & CHEST-ABD & $1-5$ RIB & 6-13RIB & LOIN & LEG \\
\hline \multicolumn{17}{|l|}{$\overline{\mathrm{LL}}$} \\
\hline $\mathrm{RP}$ & 0.3195 & & & & & & & & & & & & & & & \\
\hline RW & 0.1796 & 0.6496 & & & & & & & & & & & & & & \\
\hline CCI & 0.0336 & 0.4865 & 0.4690 & 0.6923 & & & & & & & & & & & & \\
\hline LCI & -0.5058 & 0.3588 & 0.7530 & 0.0277 & 0.3853 & & & & & & & & & & & \\
\hline $3-4 \mathrm{ST}$ & 0.0798 & 0.4450 & 0.3317 & -0.4834 & -0.0402 & 0.2605 & & & & & & & & & & \\
\hline SHO & 0.3965 & 0.5853 & 0.5068 & 0.5877 & 0.8513 & 0.1754 & 0.0558 & 0.4754 & 0.5131 & & & & & & & \\
\hline NECK & 0.4678 & 0.6702 & 0.5100 & 0.1329 & 0.5811 & 0.1345 & 0.3069 & 0.4873 & 0.2004 & 0.7108 & & & & & & \\
\hline CHEST-ABD & 0.1275 & 0.1388 & 0.1780 & 0.7734 & 0.7844 & 0.0657 & -0.3418 & 0.3156 & 0.6112 & 0.6759 & 0.3673 & & & & & \\
\hline 1-5RIB & 0.2032 & 0.1003 & 0.1486 & 0.7440 & 0.6830 & -0.0131 & -0.3076 & 0.2740 & 0.5422 & 0.6701 & 0.3162 & 0.6632 & & & & \\
\hline 6-13RIB & 0.3818 & 0.3853 & 0.3908 & 0.5848 & 0.7431 & -0.0901 & -0.0077 & 0.3609 & 0.4796 & 0.7978 & 0.5786 & 0.5669 & 0.7157 & & & \\
\hline LOIN & 0.2014 & 0.4069 & 0.3808 & 0.6691 & 0.8151 & 0.1959 & -0.1888 & 0.5112 & 0.5999 & 0.7707 & 0.5054 & 0.6837 & 0.7042 & 0.8029 & & \\
\hline
\end{tabular}

SW - shrunk weight; BEW - breast edge width; WH - height at the withers (shoulder); BCS - body condition score; 3-4S-US - tissue thickness at 3rd and 4th sternebrae obtained by ultrasound; LD-US - loin depth obtained by ultrasound; HCW - hot carcass weight; CCW - cold carcass weight; CCD - commercial carcass dressing; CIL - carcass inner length; COL - carcass outer length; CONF - carcass conformation; FC - carcass fat cover; CD - chest depth; LP - leg perimeter; LL - length of the leg; RW - rump width; CW - chest width; CCI - carcass compactness index; LCI - leg compactness index; 3-4ST - tissue thickness on the 3rd-4th sternebrae measured with a caliper; LD - loin depth, in cm; LEA - loin eye area; SHO - weight of the shoulder; NECK - weight of the neck; CHEST-ABD - weight of the chest-abdominal cut; 1-5RIB - weight of the uncovered rib; 6-13-RIB - weight of the ribs; LOIN - weight of the loin; LEG - weight of the leg. 
Several authors have referenced high and positive correlations between measures of size of the carcass in different species (Shahim et al., 1993; Boccard et al., 1964), confirming what was observed in this study. According to Boccard et al. (1964), the balanced growth is more manifested by the increase in the widths (muscle and adipose tissue) than the increase in bone tissue, so it is more natural to find high correlations between hot carcass weights and measures of dimension which also express width than among measures that express length, which can also be found in this experiment, except for the value presented by the circumference (perimeter) of the leg.

The low correlations between hot carcass weight and thickness of the tissue found in this work in the region of sternebrae may be the result of the differences in maturity between breed groups and sexes, which is in agreement with Cadavez (2004), who, using different weights of maturity, reduced the power of the inter-correlations between measures of body size and decreased the strength of the correlations between HCW and measures of dimension.

The conduction of factor analysis allowed for condensing the information contained in the correlations between pairs of the 32 original variables into four common factors, linearly independent functions of the original variables. These explained $77.2 \%(46.32,14.69,12.57$ and $3.60 \%)$ of the variability in the 32 original variables, leaving $22.8 \%$ for the 32 single factors, characteristic of each variable. The contribution of each of the original variables for each factor can be evaluated by their loads (correlations among variables vs. factor) (Table 5).

Variables with high loads on the same factor, very correlated among themselves, carry redundant information, so their simultaneous use as independent variables in the multiple regression models can cause problems of collinearity in the models, that is, in addition to not improving the accuracy of the models, it can cause instability in the estimation of regression coefficients (Shahin \& Hassan, 2000). Thus, analysis of the factors has been regarded as an important technique in the description of the covariance between the measurements of body size and carcass composition.

Moreover, the variables with significant contributions for the common factors carry different additional information.

The commonality is the portion of variance explained by the extracted group of common factors, i.e., it is the partition of the variance of each of the original variables in a common portion, shared with other variables, and one portion specific to a particular variable (single factor). The commonality was high and showed values higher than
0.80 for the characteristics and measures of size (weight, length and width) of the carcass. This may indicate that the variance of the measures of the carcass dimension is explained by their inter-correlations with other measures.

The analysis of the first factor was characterized by higher and positive loads in weight at fasting, brisket, body condition, measures of sternebrae and loin depth (by ultrasound), loin eye area, hot and cold carcass weights, conformation, width of the chest, carcass compactness index, loin depth (measured with a caliper), shoulder, chestabdomen, uncovered rib, rib, loin and leg. Thus, the hot carcass weight was chosen as the identifying characteristic of Factor 1, for being objective and easier to be obtained,

Table 5 - Loads, commonality, single factor and variation explained by the four common factors after rotation

\begin{tabular}{|c|c|c|c|c|c|c|}
\hline \multirow{2}{*}{ Variable } & \multicolumn{4}{|c|}{ Loads } & \multirow{2}{*}{ Commonality } & \multirow{2}{*}{$\begin{array}{l}\text { Single } \\
\text { factor }\end{array}$} \\
\hline & Factor 1 & Factor 2 & Factor 3 & Factor 4 & & \\
\hline SW & 0.8860 & 0.1046 & 0.4115 & -0.0108 & 0.9653 & 0.0347 \\
\hline BEW & 0.7966 & -0.0528 & -0.0352 & 0.1639 & 0.6655 & 0.3345 \\
\hline WH & 0.3846 & -0.0445 & 0.8047 & -0.1305 & 0.8146 & 0.1854 \\
\hline $\mathrm{BCS}$ & 0.6486 & 0.2962 & -0.5038 & -0.1380 & 0.7814 & 0.2186 \\
\hline 3-4S-US & 0.7231 & 0.1826 & 0.0974 & -0.1128 & 0.5785 & 0.4215 \\
\hline LD-US & 0.7981 & 0.2107 & 0.0817 & -0.0715 & 0.6932 & 0.3068 \\
\hline $\mathrm{HCW}$ & 0.8531 & 0.2864 & 0.4042 & -0.0013 & 0.9732 & 0.0268 \\
\hline $\mathrm{CCW}$ & 0.8434 & 0.3152 & 0.4045 & -0.0106 & 0.9745 & 0.0255 \\
\hline CCD & -0.0513 & 0.6637 & 0.0086 & 0.0339 & 0.4444 & 0.5556 \\
\hline CIL & 0.4087 & -0.0298 & 0.8394 & -0.0165 & 0.8729 & 0.1271 \\
\hline $\mathrm{COL}$ & 0.4096 & -0.0072 & 0.8218 & 0.0389 & 0.8448 & 0.1552 \\
\hline CONF & 0.5050 & 0.6184 & -0.0701 & 0.1090 & 0.6543 & 0.3457 \\
\hline $\mathrm{FC}$ & 0.1209 & 0.6930 & -0.1816 & 0.0063 & 0.5280 & 0.4720 \\
\hline $\mathrm{CD}$ & 0.4857 & 0.3082 & 0.5956 & -0.1792 & 0.7179 & 0.2821 \\
\hline LP & -0.1001 & 0.6544 & 0.2747 & -0.4836 & 0.7476 & 0.2524 \\
\hline LL & -0.0738 & 0.0031 & 0.9237 & -0.0340 & 0.8599 & 0.1401 \\
\hline RP & 0.1576 & 0.7004 & 0.3282 & -0.4063 & 0.7883 & 0.2117 \\
\hline RW & 0.2507 & 0.6677 & 0.2318 & -0.3007 & 0.6529 & 0.3471 \\
\hline $\mathrm{CW}$ & 0.8523 & -0.1800 & 0.1160 & 0.3317 & 0.8824 & 0.1176 \\
\hline CCI & 0.8751 & 0.3973 & 0.1331 & -0.0338 & 0.9425 & 0.0575 \\
\hline LCI & 0.2793 & 0.6018 & -0.4377 & -0.2676 & 0.7035 & 0.2965 \\
\hline $3-4 \mathrm{ST}$ & -0.1981 & 0.1980 & 0.0349 & -0.9046 & 0.8980 & 0.1020 \\
\hline LD & 0.4432 & 0.5547 & -0.0137 & -0.0864 & 0.5118 & 0.4882 \\
\hline LEA & 0.7675 & 0.1598 & -0.1532 & 0.1665 & 0.6659 & 0.3341 \\
\hline SHO & 0.7449 & 0.3462 & 0.4882 & -0.1206 & 0.9277 & 0.0723 \\
\hline NECK & 0.3229 & 0.5281 & 0.5290 & -0.2710 & 0.7365 & 0.2635 \\
\hline CHEST-ABD & D 0.7911 & 0.0743 & 0.2292 & 0.2628 & 0.7531 & 0.2469 \\
\hline $1-5 \mathrm{RIB}$ & 0.7905 & 0.0991 & 0.3136 & 0.1678 & 0.7613 & 0.2387 \\
\hline 6-13RIB & 0.7029 & 0.1881 & 0.4699 & -0.0535 & 0.7532 & 0.2468 \\
\hline LOIN & 0.7994 & 0.2833 & 0.2744 & 0.1108 & 0.8070 & 0.1930 \\
\hline LEG & 0.8806 & 0.1480 & 0.3686 & 0.0955 & 0.9425 & 0.0575 \\
\hline EV & 0.4632 & 0.1469 & 0.1257 & 0.0360 & & \\
\hline Description & n HCW & $\mathrm{RP}$ & LL & $3-4 \mathrm{ST}$ & & \\
\hline
\end{tabular}

SW - shrunk weight (weight at fasting); BEW - breast edge width; WH - height at the withers; BCS - body condition score; 3-4S-US - tissue thickness at 3rd and 4th sternebrae obtained by ultrasound; LD-US - loin depth obtained by ultrasound; HCW - hot carcass weight; CCW - cold carcass weight; CCD - commercial carcas dressing; CIL - carcass inner length; COL - carcass outer length; CONF - carcass conformation; FC - carcass fat cover; CD - chest depth; LP - leg perimeter; LL - length of the leg; RW - rump width; CW - chest width; CCI - carcass compactness index; LCI - leg compactness index; 3-4ST - tissue thickness on the 3rd-4th sternebrae measured with a caliper; LD - loin depth, in cm; LEA - loin eye area; SHO - weigh of the shoulder; NECK - weight of the neck; CHEST-ABD - weight of the chestabdominal cut; 1-5RIB - weight of the uncovered rib; 6-13RIB - weight of the ribs; LOIN - weight of the loin; LEG - weight of the leg; EV - explained variance. 
and for explaining $46.32 \%$ of the variation in the original variables.

The second common factor was identified as rump perimeter, since it is characterized by high and positive loads in the measures of perimeter, width, indices (commercial carcass dressing and leg compactness index) and subjective evaluations (conformation and fat cover) of the carcass, and explained $14.69 \%$ of the variation found in the original variables.

The third factor could be identified as leg length, since it is characterized by high and positive charges in the biometric measures of carcass, explaining $12.57 \%$ of the variability found in the original variables. The fourth common factor was identified as measures of tissue at the 3rd and 4th sternebrae, by presenting high and negative loads in the measures of thickness $(\mathrm{cm})$ of the subcutaneous tissue in the region of the sternebrae, explaining $3.60 \%$ of the variability found in the original variables.

The four common factors explained $97 \%$ of the variability of the $\mathrm{HCW}$, and only $3 \%$ of the variability of this variable is attributable to the same single factor. Thus, the communalities for measures of carcass size (perimeters and width) were high and the four common factors explained between 65 and $88 \%$ of the variability in the measurements, with 35 and $12 \%$ of the their variability due to the single factors of each variable. With regard to the characteristics of the length, commonalities were also high, all of them higher than 0.8146 and the four factors explained between 81.46 and $87.29 \%$ of the variability of the characteristics, and only 18 and $13 \%$ of this variability are due to their single factor. For measures of tissue deposition in the sterna region, all four factors explained a high percentage of the variation in characteristics measured on the carcass (not collected by ultrasound), ranging between $86.19 \%$ and $89.80 \%$ (3-4ST), leaving only 14 and $11 \%$ of unexplained variation in the characteristic values of each variable.

Based on these results, the group of the first 32 variables could be reduced to four variables that contained most of the relevantinformation of theinitial group, information provided by their inter-correlations. The selected variables were: 1 - hot carcass weight ( $\mathrm{HCW}$ ), 2 - rump perimeter (RP), 3 - leg length (LL), 4 - measures of the tissue on the 3rd and 4 th sternebrae $(3-4 \mathrm{ST})$.

Hot carcass weight is used throughout the marketing process of the carcass and is a piece of information always available in the production systems and with a very low cost. Thus, it should be included in models to estimate the carcass composition (Kempster, 1984). Measurements of the perimeter of the rump, leg length, and tissues at the 3rd-4th sternebrae not only add information to the HCW but were also selected because they are measurements easy to be obtained on the carcass, with a measuring tape and calipers.

The four selected variables were subjected to a second factor analysis, which aimed to calculate new variables (factors), to be used as independent variables in the models to estimate the carcass composition (Table 6). Factor I showed high positive load to HCW measure and explained $45.77 \%$ of the variation found in the four original variables. Factor II, with high and positive loads for 3-4ST, explained $28.17 \%$ of the variation found in the original variables. The third factor, in turn, was identified as leg length, because of its high and positive charge, explaining $18.50 \%$ of the variation in the original variables. Lastly, Factor IV had higher high load for rump perimeter, explaining $7.54 \%$ of the variation in the original variables.

Thus, the characteristics and common factors were used to determine the amount and proportion of muscles, bones and carcass fat, according to the proposed models.

The estimate model of muscle weight showed no bias with respect to the sex or breed group, but showed a deviation to estimate it among the breed groups, which was higher for the $1 / 2$ Anglo Nubian than for $1 / 2$ Boer, with no differences among the others. The estimate model of the proportion of muscles showed neither biases related to sex or breed group nor deviations.

Concerning the muscles, the models presented to estimate muscle weight showed high values for the coefficient of determination and low values for residual standard deviation, showing the goodness of fit of the models to the features. The estimate of the regression coefficients was fairly stable since the inclusion of new independent variables did not cause major changes in the estimate of the regression coefficients of the variables already present in the models.

The use of HCW as the only independent variable explained much of the variation found in muscle weight $\left(\mathrm{R}^{2}=0.84\right)$, showing no biases or deviations. The admission of other variables in model 2 slightly changed the coefficient of determination and showed a deviation for the breed

Table 6 - Loads and variances explained by the four common factors built from the four original selected variables

\begin{tabular}{lrrrc}
\hline Variable & Factor 1 & Factor 2 & Factor 3 & Factor 4 \\
\hline HCW & 0.9584 & -0.0756 & 0.1429 & 0.2348 \\
Rump perimeter & 0.2727 & 0.2671 & 0.1581 & 0.9106 \\
Leg length & 0.1343 & 0.0313 & 0.9816 & 0.1314 \\
3-4ST & -0.0722 & 0.9724 & 0.0307 & 0.2197 \\
Explained variance & 0.4577 & 0.2817 & 0.1850 & 0.0754 \\
\hline
\end{tabular}

HCW - hot carcass weight $(\mathrm{kg})$; 3-4ST - depth of the tissues between the 3rd and 4th sternebrae measured with a caliper $(\mathrm{cm})$. 
groups. However, by reducing the direct characteristics in the factors, in model 3, the $\mathrm{HCW}$ remained the main feature responsible for determining the muscle weight $\left(\mathrm{R}^{2}=0.76\right)$, but also showing a deviation for the breed groups. In this model, the addition of characteristics of length (Factor II) and perimeter (Factor III) led to a significant improvement in the quality of fit of the model with a $16 \%$ increase in the coefficient of determination. Anyway, it seems that HCW is the main feature responsible for determining the weight of muscle in the carcass. Thus, to determine the proportion of muscle in the carcass, it was elucidated that other characteristics, because they have not been included in any of the models, do not add any information to the HCW. In spite of having a low regression coefficient, around 0.11 and 0.13 , HCW was the only variable capable of explaining this feature.

Cadavez et al. (2002) observed an improvement in the quality of fit of the models to estimate muscle when a variable of fat thickness was added to the $\mathrm{HCW}$, which was not observed in this study.

Contrary to the findings of Cadavez (2004), the models proposed for determining the estimate of muscles showed no bias regarding sex.

In the estimate of the proportion of muscle, HCW explained a small reduction of this variation, but there was no bias, showing no differences between different breed groups and genders in the estimate of muscle composition in the carcass, agreeing with the findings of Taylor et al. (1989).

In models developed by multiple linear regression, Cadavez et al. (2002) report that models for estimate of the muscle weight tend to be dominated by live weight or hot carcass weight, as they explain much of the variation found in muscle weight, since there is a high correlation between carcass weight and indicators of muscularity, which was also observed in this experiment with 0.94 of correlation between muscle weight and hot carcass weights. The inclusion of additional variables in the model only helped to increase the quality of fit of the model, so there is no need to develop estimate models per breed groups, since fairly accurate models were obtained with the HCW.

The results achieved in this work show that because $\mathrm{HCW}$ is a piece of information always available, it should be included as the first variable in the models for estimating carcass composition without needing others to validate the assumptions.

In relation to the fat, the models presented to estimate fat weight usually presented low values for the coefficient of determination and residual standard deviation, showing the low quality of fit of the models for the characteristics. The estimate of the regression coefficients showed a slight instability, with the inclusion of new independent variables, indicating the absence of problems concerning collinearity.

The use of HCW as single independent variable was not sufficient to estimate the weight and proportion of fat, since it explained little of the variance found for these characteristics $\left(\mathrm{R}^{2}=0.21\right.$ and $\mathrm{R}^{2}=0.0031$, respectively), presenting bias for sex in the estimation of weight and proportion of fat and also for breed group in the estimation of its proportion, indicating the need to develop specific models for estimating weight and fat ratio for sex and proportion of fat for each breed group. This may happen because the adipose tissue presents late maturation in relation to carcass weight (Butterfield \& Thompson, 1983) and the increase in weight of animals leads to major changes of the tissue, reducing the correlation among them. A correlation of 0.46 between the weight of the fat and $\mathrm{HCW}$ was found in this study.

According to Taylor et al. (1989), within a given breed, females have a higher fat content in carcass than males at same weight and the same age; this difference reflects the greater maturity of the females rather than the different fat deposition rate between the sexes. Moreover, the bias can result from differences in the degree of maturity between animals of different sex within the same breed group and among breeds that present differences in the carcass composition at the same weight (Taylor et al., 1989) which explains the finding in this experiment, since the animals were at different ages at slaughter.

However, the $\mathrm{HCW}$ is no longer the first variable admitted in model 2, both for estimation of weight and to estimate the proportion of fat, and the measures of perimeter and length ended up by dominating the models of weight and proportion, respectively, since they were the first independent variables in the model and also those that explained most of the variation observed. The admission of other variables in model 2 changed the coefficient of determination and brought an increase of 20 percentage points for weight and 16 percentage points for fat ratio. However, with the improvement shown by the coefficient of determination, neither biases nor deviations were found.

With the use of the factors in model 3, measures of perimeter (Factor IV) and length (Factor III) continued to dominate the model of estimates of weight and fat ratio, respectively. In the model of the estimate of weight, the addition of Factor I and III caused a significant improvement in the quality of fit of the model with a $24 \%$ increase in the regression coefficient.

To estimate the percentage of fat, factors III and IV were admitted, respectively. Hot carcass weight (Factor I) 
was not admitted to either model 2 or model 3, elucidating that in the conditions studied, HCW alone does not add any information on measures of length and perimeter in the estimate of proportion of fat.

When compared with the same age and weight, females should have higher fat content in carcass (Taylor et al., 1989), reflecting their greater maturity, which was not found in this experiment by the low weight of the carcasses assessed.

To estimate the bones, the use of HCW as the only independent variable explained much of the variation found in the weight of the bones $\left(\mathrm{R}^{2}=0.62\right)$, but showed biases and deviations. The admission of other variables in model 2 caused an improvement in the coefficient of determination, but not enough to eliminate biases and variances, which continued to exist. With the reduction in direct characteristics in factors in model 3, the HCW remained the main feature responsible for determining the weight of the bones $\left(\mathrm{R}^{2}=0.55\right)$. In this model, the characteristic of length of the leg (Factor III) was also included; it caused a significant improvement in the quality of fit of the model with a $20 \%$ increase in the coefficient of determination, but it continued to show biases and deviations.

The models presented for estimating the weight of the bones showed high values of the coefficient of determination and low values for the residual standard deviation, showing certain quality of fit of models to data. The inclusion of additional independent variables in the model hardly caused major changes in the estimate of the regression coefficients of the variables already present in it. In estimating the proportion of bones, the models showed low values for the coefficient of determination and high residual standard deviation when compared with the estimate of weight, which indicates lack of fit of models to data.

Hot carcass weight as the only independent variable was not sufficient to explain the variation found in the proportion of carcass bones, showing biases related to gender and breed group. The admission of characteristics of leg length and rump perimeter in model 2 improved the quality of the fit, but not enough to eliminate biases. However, with the reduction in direct characteristics in factors in model 3, the $\mathrm{HCW}$ was no longer the first variable accepted in the model, and the measure of the perimeter of the rump took over the model since it was the first independent variable admitted. However, it was not enough to explain the variation in the proportion of bones, and with the inclusion of variable length (Factor III) and weight (Factor I) it showed an improvement in the quality of the adjustment within 24 percentage points, yet still maintaining the bias.
In estimating the weight of the bones in model 3 and the proportion of bone in models 2 and 3 , the characteristic 3-4ST (Factor II), for not having been included, makes it clear that alone it does not add any information to the other variables present in models.

The models proposed for determining the weight of the bones were more reliable than models for estimating their proportion, but both were inaccurate and biased for gender and breed group.

According to Butterfield \& Thompson (1983), the maturity pattern of bone tissue has differences among animals with different weights; this means that animals of similar genetic groups when compared with the same weight can differ as to the deposition of bone tissue. However, this difference vanishes when the animals are compared at the same degree of maturity. A correlation coefficient of 0.79 between weight of the bones and HCW was found in this experiment.

The results show that the $\mathrm{HCW}$ is not enough to estimate the amount of bone from the carcass. Measures of carcass dimension should be used in addition. However, these models seem to be little suited to this estimate.

\section{Conclusions}

The analysis of common factors is a good alternative to the traditional linear regression, allowing for estimation of regression coefficients with greater stability, especially for the muscles. The weight of the carcass muscle can be estimated with high accuracy from simple models, without the need for information on sex and breed, and they may be constructed based on the weight of the carcass. The models of fat and bones estimate were inaccurate.

\section{References}

ARGuello, A.; CAPOTE, J.; GINÉS, R. et al. Prediction of kid carcass composition by use of join dissection. Livestock Producition Science, v.67, p.293-295, 2001.

BOCCARD, R.; DUMONT, B.L.O.; PEYRON, C. Etude de la producion de la viande chez les ovins. VIII : Relations entre les dimensions de la carcasse d'agneau. Annales de Zootechnie, v.13, n.4, p.367-378, 1964.

BUTTERFIELD, R. New concepts of sheep growth. Sidney: University of Sidney, Department of Veterinary Anatomy, 1988. 468 p.

BUTTERFIELD, R.M.; THOMPSON, J.M. Changes in body composition relative to weight and maturity of large and small strains of Australian Merino Rams. 4. Fat depots and bones. Animal Production, v.37, p.423-431, 1983.

CADAVEZ, V.A.; RODRIGUES, S.; PEREIRA, E. et.al. Predicción de la composición de la canal de cabritos por ultrasonografia in vivo. ITEA, n.98 A (1), p.39-50, 2002.

CADAVEZ, V.A.P. Ultrassonografia para avaliar in vivo e ex vivo carcaças de ovinos: estudos nas raças Churra Galega 
Bragançana e Suffolk. 2004. 289f. Tese (Doutorado em Zootecnia) - Universidade de Trás-os-Montes e Alto D'ouro, Vila Real, Portugal.

COLOMER-ROCHER, F.C.; MORAND-FHER, P.; KIRTON, A.H. Standard methods and procedures for goat carcass evaluation, jointing and tissue separation. Livestock Production Science, v.17, p.149-159, 1987.

HOFFMANN, R.; VIEIRA, S. Análise de regressão. Uma introdução à econometria. 2.ed. São Paulo: Hucitec, 1987. 379p.

JOHNSON, R.A.; WICHERN, D.W. Applied multivariate statistical analysis. 2.ed. New Jersey: Prentice Hall, 1988. 607p.

KEMPSTER, A.J. Cost-benefit analysis of in vivo estimates of body composition in meat animals. In: In vivo measurements of body composition in meat animals. Barking Essex, UK: Ed. Lister, Elsevier Applied Science Publischer, 1984. p.191-203.

LILLIEFORS, H.W. On the Kolmogorov-Smirnov test for normality with mean and variance unknown. Journal Statistics Association, v.62, p.399-402, 1967.

MONTGOMERY, D.C. Design and analysis of experiments. 4.ed. New York: John Wiley \& Sons, 1997. 883p.

NETER, J.; WASSERMAN, W.; KUNTER, M.H. Applied linear statistical models: regression, analysis of variance and experimental design. 3.ed. Sidney: 1990. 1181p.
SAÑUDO, C.; SIERRA, I. Calidad de la canal en la especie ovina. Ovino, n.1, p.127-53, 1986.

SHAHIN, K.A.; HASSAN, N.S. Sources of shared variability among body shape characters at marketing age in New Zealand white and Egyptian rabbit breeds. Annales Zootechnie, n.5, v.49, p.435-445, 2000.

SHAHIN, K.A.; SOLIMAN, A.M.; MOUKHTAR, A.E. Sources of shared variability for the egiptian buffalo body shape (conformation). Livestock Production Science, v.36, n.4, p.323-334, 1993.

SILVA SOBRINHO, A.G.; GONZAGA NETO, S. [2006]. Produção de carne caprina e cortes da carcaça. Available at: $<\mathrm{http}: / / \mathrm{www}$. capritec.com.br/pdf/produção_carnecaprina.pdf.> Accessed on: Nov. 14, 2007.

SILVA, C.M.; CAETANO, A.; CARDOSO, L.G. Sistema de planimetria digitalizada. In: JORNADA CIENTÍFICA DA ASSOCIAÇÃO DE DOCENTES, 18., 1993, Botucatu. Anais... Botucatu: Universidade Estadual Paulista, 1993. p.109.

TAYLOR, S.C.S.; MURRAY, J.I.; THONNEY M.L. Breed and sex differences among equally mature sheep and goats. 5: Lipid and dry tissue. Animal Production, v.49, p.411-422, 1989.

TOPEL, D.; KAUFFMAN, R. Live animal and carcass composition measurements. In: TOPEL, D. (Ed.) Designing foods: animal production options in the marketplace. Washington, D.C.: National Academic Press, 1988. p.258-272. 